\title{
Diyadin İlçesinde Bulunan Jeotermal Enerji Kaynağının Mühendislik ve Ekonomik Açıdan İncelenmesi
}

\author{
Samed ŞENTÜRK ${ }^{1}$, Arzu ŞENCAN ŞAHİN *2 \\ ${ }^{1}$ Isparta Uygulamalı Bilimler Üniversitesi, Teknoloji Fakültesi, Makine Mühendisliği Bölümü, 32260, Isparta \\ ${ }^{2}$ Isparta Uygulamalı Bilimler Üniversitesi, Teknoloji Fakültesi, Makine Mühendisliği Bölümü, 32260, Isparta
}

(Alınış / Received: 06.05.2019, Kabul / Accepted: 29.07.2019)

\author{
Anahtar Kelimeler \\ Organik Rankine Çevrimi, \\ Jeotermal Enerji, \\ Isitma, \\ Seracılık
}

\begin{abstract}
Özet: Gelişen ve günümüz enerji teknolojileri arasında yer alan jeotermal enerji kaynakları elektrik enerjisi üretimi, ısıtma sistemleri ve tarım uygulamaları gibi birçok alanda yaygın bir şekilde kullanılmaktadır. Jeotermal kaynakların yenilenebilir enerji teknolojileri arasında yer alması, çevre dostu olması, ekonomik bir şekilde faydalanılması özellikle Doğu Anadolu bölgelerinde zor şartlarda yapılan tarım ve seracılık faaliyetlerinde etkin bir şekilde kullanılmasını sağlamaktadır. Organik Rankine Çevrimi akıșkan olarak su yerine, buharlaşma sıcaklığı daha düşük olan organik bazlı akışkanların kullanılmasıyla enerji ve güç üretimi sağlayan bir çevrimdir. Atık ısı kaynakları, jeotermal enerji, güneş enerjisi gibi birçok ısı kaynağı Organik Rankine Çeviriminde kullanılabilmektedir.
\end{abstract}

$\mathrm{Bu}$ çalışmada Ağrı ili Diyadin ilçesinde bulunan ve etkin bir şekilde seracılık faaliyetlerinde kullanılan jeotermal enerji kaynağının düşük ölçekte bir Organik Rankine Çevriminde kullanılabilirliği araştırılmıștır. Ayrıca jeotermal enerji kaynağından yararlanılarak bölgedeki konutların ısıtılması durumunda oluşabilecek avantaj ve dezavantajlar da incelenmiștir. Yapılan çalıșmanın bölgedeki enerji ihtiyacının çözümünde katkısı olacağı düşünülmektedir.

\section{Engineering and Economic Investigation of Geothermal Energy Sources in Diyadin District}

\section{Keywords}

Organic Rankine Cycle, Geothermal Energy,

Heating,

Greenhousing

\begin{abstract}
Geothermal energy sources, which are among the developing and current energy technologies, are widely used in many fields such as electricity generation, heating systems and agricultural applications. The fact that geothermal resources are included among the renewable energy technologies, being environmentally friendly and utilizing them in an economic way ensures that they can be used effectively in agricultural and greenhouse activities carried out under difficult conditions especially in Eastern Anatolia. Organic Rankine Cycle is a cycle that provides energy and power generation by using organic based fluids with a lower evaporation temperature instead of water as a fluid. Many heat sources such as waste heat sources, geothermal energy and solar energy can be used in Organic Rankine Cycle.

In this study, the usability of the geothermal energy source in the Diyadin district of Ağrı province, which is used effectively in greenhouse cultivation, in a low - rank Organic Rankine Cycle has been investigated. In addition, advantages and disadvantages of geothermal energy sources are investigated. It is thought that the study will contribute to the solution of the energy need in the region.
\end{abstract}




\section{Giriş}

Ülkemizin nüfusu her geçen gün artmaktadır. TÜíK 2017 verilerine göre ülkemizin şu anki nüfusu 80 milyon 810 bin kişidir. Bu oranın 2023 yılında 86 milyon 907 bine, 2040 yılında ise 100 milyon 330 bin kişiye çıkması tahmin edilmektedir [1]. Artan bu nüfus oranıyla birlikte enerji ihtiyacı da her geçen gün artış göstermektedir. Türkiye elektrik enerjisi tüketimi 2017 yılında bir önceki ylla göre \%5,6 artarak 294,9 $\mathrm{kWh}$, elektrik üretimi ise bir önceki yıla göre $\% 7,7$ oranında artarak 295 milyar kWh olarak gerçekleşmiştir [2]. $\mathrm{Bu}$ veriler doğrultusunda ülkemizin enerji ihtiyacı her geçen gün artmaktadır.

Türkiye'de 2017 yılındaki elektrik üretiminin yaklașık \%70'i kömür, doğalgaz gibi fosil kaynaklardan elde edilmektedir[2]. Bu kaynakların büyük bir kısmının ithal edilmesi, döviz kurlarındaki dalgalanmalar ve yenilenebilir enerji kaynaklarının nispeten daha az kullanılması ülkemize büyük bir maliyet yüklemektedir. Fosil kaynakların çevreye verdiği zararlar, ozon tabakasının delinmesi ve özellikle küresel ısınmaya etkisinden dolayı bu kaynakların kullanımı birçok ülkede kısıtlamaya gidilmiştir.

Yenilenebilir enerji kaynakları arasında güneş enerjisi, rüzgar enerjisi, biyokütle, hidroelektrik enerji jeotermal enerji gibi birçok kaynak bulunmaktadır. Bu kaynakların kullanımı hem yerli hem de milli kaynaklar içerisinde bulunmasından dolayı birçok ülke tarafından yaygın bir şekilde kullanılmaktadır. Yenilenebilir enerji sistemlerine verilen teşvik ve hibelerin artmasıyla bu oran ülkemizde gittikçe artış göstermektedir. Güneș ve rüzgar enerji sistemlerinin kurulum aşamalarında kullanılan ekipman ve malzemelerin çoğunun ithal edilmesi, ilk yatırım maliyetlerinin yüksek olması ve mevcut enerji kaynaklarının mevsimlere göre değişkenlik göstermesinden dolayı bu kaynakların kullanımını kısıtlamaktadır. Jeotermal enerji kaynakları ise mevsimsel durumlardan çok etkilenmemekte ve bölgede yapılan uygun sondaj çalışmalarıyla hemen kullanıma sunulabilmektedir.

$\mathrm{Bu}$ çalışmada Ağrı ili Diyadin ilçesinde bulunan Jeotermal enerji sahasının termodinamik incelemesi yapılmıștır. Yapılan çalışmalarla bölgede kurulması planlanan Organik Rankine Santrali ile bölgedeki enerji ihtiyacının bir kısmının karşılanması hedeflenmiştir. Ayrıca bölgede jeotermal enerjiyle yapılan isitma sistemleri ve seracılık faaliyetlerinin ekonomiye katkısı da incelenmiştir. Yapılan çalışmanın bölgedeki enerji sorunlarına çözüm olması hedeflenmektedir.

\section{Jeotermal Enerji Kaynakları}

Jeotermal enerji; yerin altında birikmiş enerjinin kar, yağmur suyu gibi akışkanların yer kabuğuna sızarak bu biriken enerjiyi yeryüzüne çıarmasıyla oluşmaktadır (Șekil 1).

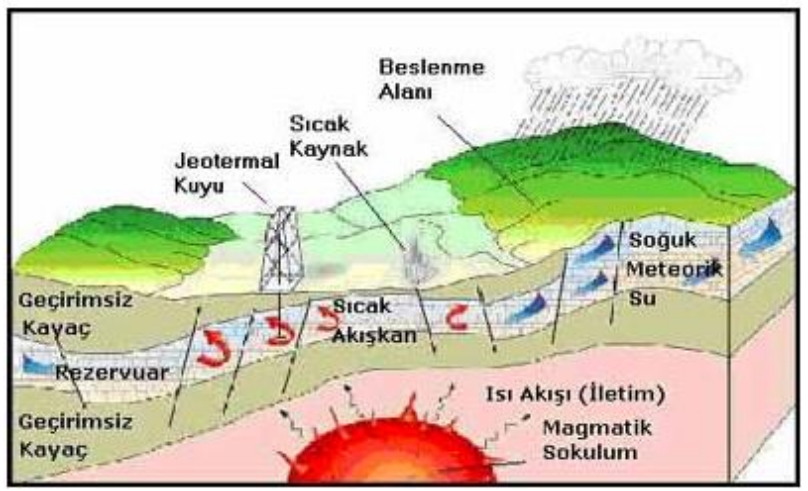

Şekil 1. Jeotermal Sistemin Şematik Gösterimi [3]

Yüzyıllar boyunca hava olaylarının meydana gelmesiyle yer kabuğu altına sızan yağmur ve kar suları, yer kabuğunun derinliklerinde bulunan magmanın isı akışıyla harekete geçmektedir. $\mathrm{Bu}$ hareketler yeryüzünün herhangi bir bölgesinde çatlak veya kırıklarla yüzeye ulaşır. Böylece ısınan akışkan herhangi bir işleme gerek kalmadan, yeryüzünde enerjili ve mineral bakımından zengin bir 151 kaynağına dönüşür.

Ülkemizde birçok bölgede jeotermal enerji kaynakları bulunmaktadır. Özellikle fay hatlarının ve deprem levhalarının hareketiyle meydana gelen kırık ve çatlaklarla jeotermal enerji kaynakları yüzey ulaştırır. Dolayısılya deprem bölgelerinde jeotermal enerji kaynakları daha fazla bulunmaktadır (Şekil 2).

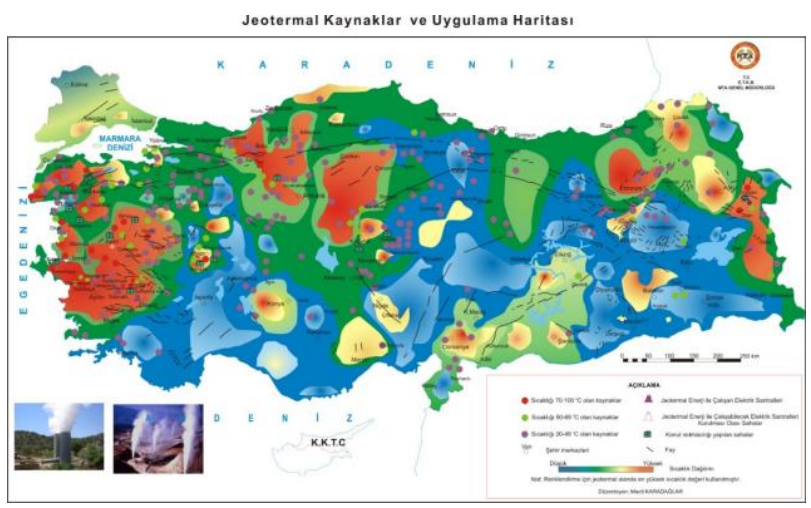

Şekil 2.Türkiye Jeotermal Enerji Haritası [4]

\section{Araştırma Bulguları}

Bu çalışmada Doğu Anadolu Bölgesinin Yukarı Murat bölümünde yer alan, Ağrı ili sınırlarında bulunan Diyadin ilçesine bağlı Çermik jeotermal enerji sahasının incelenmesi yapılmıştır. Diyadin doğal kaynakları ile oldukça eski bir yerleşim yeridir. Ağrı merkezine $60 \mathrm{~km}$, Doğubayazıt ilçesine ise yaklaşı 50 km uzaklıktadır. Gürbulak sınır kapısı üzerinde 
bulunan uluslararası karayoluna bağlantı noktasıyla önemli bir bölgede yer almaktadır (Şekil 3).

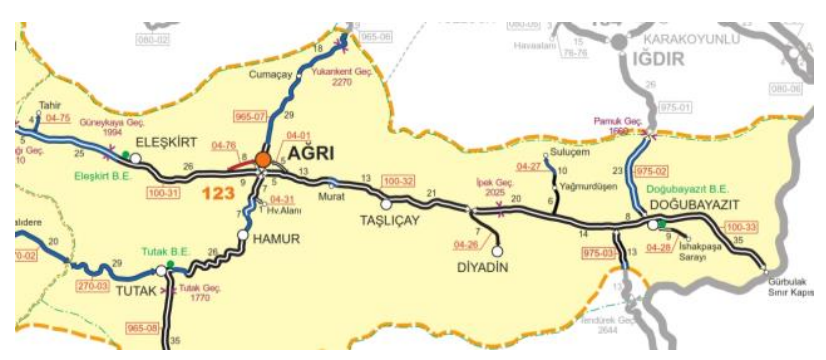

Şekil 3. Ağrı İlinin Haritası [5]

Bölgenin bulunduğu konum dikkate alındığında özellikle seracılık faaliyetlerinde ihracatta önemli bir bölgede yer almasını sağlamaktadır.

Diyadin(Çermik) jeotermal enerji sahası ilk olarak Maden Tetkik ve Arama Genel Müdürlüğü (MTA) tarafından 1997 yılında araştırılmaya bașlanmıştır. 1998 yılında açılan sondaj kuyularından ortalama 75oC sıcak su elde edilmiştir. Bu çalışmalar sonunda MTA tarafindan 215 metre derinliğinde 4 adet açlan sondaj kuyuları ile su sıcaklığı 78 'C' ye kadar ulaşılmıştır [6-11].

2005 yılında MTA tarafından yapılan son çalışmalar neticesinde Diyadin Çermik jeotermal enerji sahasında doğal çıkış olarak $23-70{ }^{\circ} \mathrm{C}$ ve $14 \mathrm{lt} / \mathrm{sn}$ debi ile sıcak su elde edilmiş, sondaj çalıșmalarıyla $62-78{ }^{\circ} \mathrm{C}$ ve 560,5 lt/sn debi sıcak su elde edilmiștir. MTA verilerine göre bölgenin toplam potansiyeli 87,4 MW olarak belirlenmiştir[8]. Ayrıca 2018 yılında MTA tarafında yapılan sondaj çalıșmalarıyla Ağrı ili merkezine $2 \mathrm{~km}$ uzaklıkta bulunan bölgede yaklaşık $1500 \mathrm{~m}$. derinlikte $48{ }^{\circ} \mathrm{C}$ sıcaklığında jeotermal su bulunmuștur [6-12].

\subsection{Mevcut Jeotermal Enerji Kullanımı}

\section{Konut Isıtması}

Mevcut jeotermal kaynağın kullanılmasıyla mahal ısıtması yapılmaktadır. Bölgenin kış aylarında sıcaklıklar $-35^{\circ} \mathrm{C}$ ye kadar düşmektedir. Özellikle kış aylarında sıcaklığın bu denli düşük olması bölge halkı için ısıtma giderlerini önemli miktarda artırmaktadır. Dolayısıyla jeotermal enerji kaynağın ısıtma ihtiyaçlarında kullanılması giderleri önemli ölçüde azaltmaktadır.

Türkiye'de jeotermal enerjinin ısıtma olarak kullanılması 1987 yılına dayanmaktadır. Özellikle Ege bölgesinde jeotermal kaynaklarının keşfedilmesiyle, Balıkesir(Gönen), Kütahya(Simav), Afyon, Denizli(Sarayköy) gibi bölgelerde yaygın bir şekilde kullanılmaktadır [6-12]. Tablo 1'de Türkiye'de mevcut merkezi ısıtma sistemleri görülmektedir.
Tablo 1. Türkiyede Merkezi Isıtma Sistemleri

\begin{tabular}{|l|l|l|}
\hline Yer & Tarih & $\begin{array}{l}\text { Kurulu } \\
\text { Güç,(MW) }\end{array}$ \\
\hline Gönen-Balıkesir & 1987 & 10.6 \\
\hline Simav-Kütahya & 1991 & 26.2 \\
\hline Kırşehir & 1994 & 5.6 \\
\hline $\begin{array}{l}\text { Kızılcahamam- } \\
\text { Ankara }\end{array}$ & 1995 & 17.6 \\
\hline Balçova-İzmir & 1996 & 71.3 \\
\hline Afyon & 1996 & 33.9 \\
\hline Kozaklı-Nevşehir & 1996 & 16.7 \\
\hline Sandıkl1-Afyon & 1998 & 29.3 \\
\hline Diyadin-Ağrı & 1998 & 10.9 \\
\hline Salihli-Manisa & 2002 & 17.0 \\
\hline Sarayköy-Denizli & 2002 & 8.0 \\
\hline Edremit-Balıkesir & 2004 & 6.0 \\
\hline TOPLAM & & 253 \\
\hline
\end{tabular}

Diyadin'de ise jeotermal enerji kaynağının tespit edilmesinden sonra yapılan çalışmalar neticesinde 1998 yılında ilçedeki konutların ısıtılması amacıyla faaliyetlere başlanmıștır. Isı merkezi ilk olarak 150 konut ısıtmasıyla faaliyete başlamış ve 2015 yılında 600 konutluk bir kapasiteye ulaşmıştır. Günümüzde ise sistemin eskimesi ve bakım faaliyetleri dolayısıyla 500 konut ısıtması yapılabilmektedir. Bölge hava koşullarından dolayı ısıtma 8 ay 24 saat usulüyle yapılmaktadır. Konutlara gönderilen su sıcaklığı $65^{\circ} \mathrm{C}$ olarak gerçekleşmektedir. 2019 yılı için ısıtma bedeli $30 \mathrm{TL} / \mathrm{m}^{2}$ olarak belirlenmiştir [12, 13]. Şekil 4'te Diyadin ısıtma sisteminin günümüzdeki gelişimi gösterilmiştir.

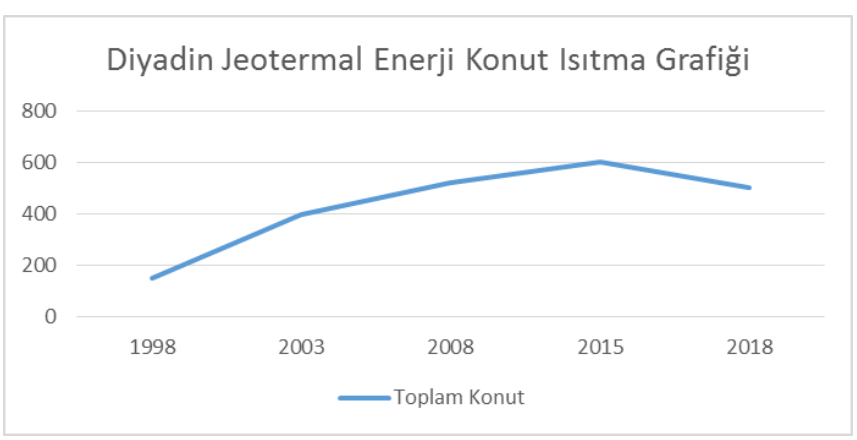

Şekil 4. Konut Isıtmasındaki Artış

\section{Sera Isıtması}

Seracılık; uygun ortam ve koşulların sağlanmasıyla bitkilerin dış ortamdan bağımsız bir şekilde büyümesi ve gelişmesi olarak açıklanabilir. Ülkemizde özellikle Akdeniz ve Ege bölgelerinde yaygın bir şekilde seracılık faaliyetleri yapılmaktadır. Seracılıkta maliyetlerin \% 70 gibi önemli bir oranını ısıtma masrafları oluşturmaktadır. Dolayısıyla bu maliyetler göz önüne alındığında jeotermal enerji kaynaklarının 
seracılık faaliyetlerinde kullanılması giderleri önemli ölçüde azaltmaktadır.

Bu kapsamda Diyadin bölgesinde 1998 yılında keşfedilen jeotermal enerji kaynağı sayesinde bölgede seracılık yapılması fikri öne sürülmüştür. Özellikle bölgenin zorlu kış şartları ve yaş sebze meyve ulaşımının kısıtlı olması bölge ekonomisine sağlayacağı katkılardan dolayı ilk etapta 8 adet kurulan serada çeşitli sebze ve meyveler yetiştirilmeye çalıșılmış ve yıllık 160 ton ürün elde edilebilmiştir. Bu olumlu gelişmeye rağmen merkezi ısıtma sisteminin yetersizliği ve hayata geçirilemeyen bir takım projeler sebebiyle deneme amaçlı seralar zamanla yok olmuştur [6-12].

İlerleyen zamanlarda pilot bir çalışma olarak kurulan seralarda topraksız tarım yapılmakta ve oldukça yüksek verim alınmaktadır. Bu şekilde topraksız tarım yapılarak arka arka üretim sağlanabilmektedir. Sri Lanka'dan ithal edilen ve hindistan cevizi kabuğu malzemesinden olan bu malzeme sayesinde toprağın kalitesine olan ihtiyaç da ortadan kalkmıştır(Şekil 5) [6-12].

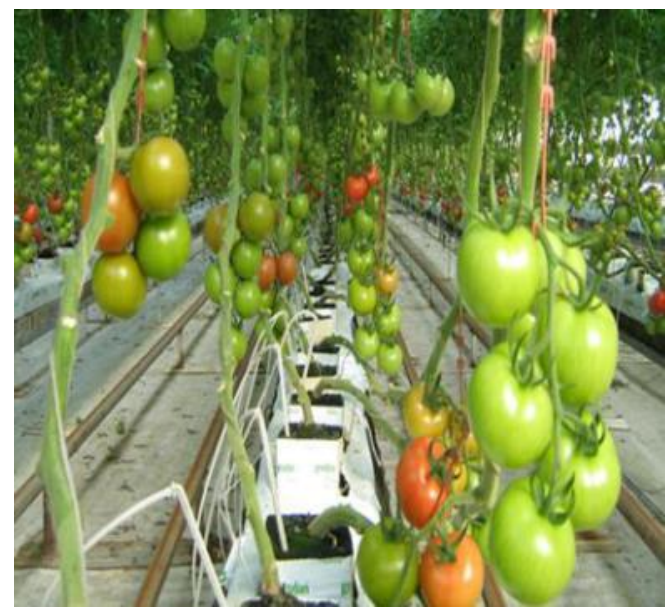

Şekil 5. Preslenmiș hindistan cevizi kabuğunda domates yetiştiriciliği

Yapılan bu çalışmalar neticesinde Diyadin ilçesinde seracılığa verilen önem giderek artmış ve 2014 yılında Belediye ve İl Özel İdaresine bağlı olarak yürütülen çalışmalar özel sektöre devredilmiştir. Özel sektöre bağlı bir işletme 40 dönümlük bir arazide 365 gün boyunca üretim yapmaktadır. Böylelikle bölgedeki tarım ve seracılık faaliyetlerinde ciddi bir şekilde artış yaşanmıştır.

Bu bölgede seracılık faaliyetleri açısından bir diğer gelişme ise Tarıma Dayalı İhtisas Organize Sera Bölgesi (TDİOSB) kurulmasıdır. 2015 yılında Tarım ve Orman Bakanlığ ile yapılan protokoller çerçevesinde 2018 yılında TDİOSB kurulması ile ilgili ihalelere başlanmıștır. Bu proje kapsamında kurulacak istihdam alanlarıyla bölgede 2000 kişilik bir iş sahası açılması öngörülmektedir.

\section{Kaplıca Turizmi}

Jeotermal enerji kaynaklarının en etkin bir şekilde kullanıldığ diğer bir alan Kaplıca (Termal) turizmdir. Ülkemizde başta Ege bölgesi olmak üzere birçok alanda termal turizm olarak tabir edilen kaplıca faaliyetleri hem şifalı su, hemde sağlık açısından önemli bir alanda görülmektedir. Özellikle Doğu ve İç Anadolu bölgelerinde kış sıcaklıklarının düşük seyretmesi ve bölge halkının mevcut ekonomik durumu göz önüne alındığında turizm açısından jeotermal enerji kaynakları kaplıca turizminde önemli noktada bulunmaktadır.

$\mathrm{Bu}$ noktadan hareketle 1998 yılında Diyadin İlçesinde çıkarılan jeotermal enerji kaynağının kaplıca ve termal turizm faaliyetlerinde değerlendirilmesi amaçlanmıştır. 1998 yılında inşaatına başlanan 4 yıldızlı bir termal otel hizmete açılmıştır. Ancak işletmenin profesyonel bir ekip tarafından yönetilmemesi, bölgenin tanıtımının yeterli bir seviyede olmaması gibi nedenlerden dolayı kısa bir sürede kapatılmıștır.

Günümüzde bölgede hali hazırda bulunan 3 özel işletme termal tesis olarak hizmet vermekte ancak yeterli profesyonelliğe ulaşamamıştır. Şekil 6'da özel bir termal işletmenin kaynak alanı gösterilmiştir.

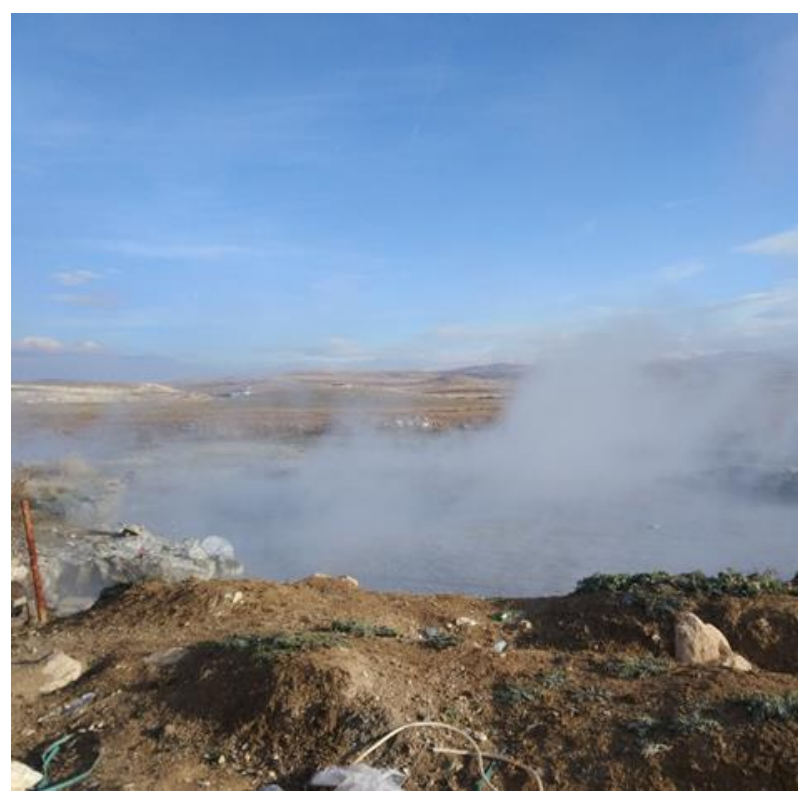

Şekil 6. Bölgede bulunan bir jeotermal kaynağl

\subsection{Jeotermal Enerjinin Organik Rankine Çevriminde Kullanılabilirliği}

Buharlı güç çevrimlerinin temelinde bulunan Rankine çevrimi, akışkanın pompa vasıtasıyla 
basınçlandırarak kazana gönderilip kızgın buhar halinde türbinden geçirilerek mekanik enerjinin elektrik enerjisine dönüştürüldüğü termodinamik bir çevrimdir. Rankine çevriminde akışkan olarak su kullanılmaktadır. Rankine çevrimi günümüzde enerji üretim sistemlerinde yaygın bir şekilde kullanılmaktadır. Rankine çevriminde suyun kızgın buhar halinde türbine gönderilmesi için çok yüksek sıcaklıklar gerekmektedir.

Organik Rankine çevrimi, çalışma akışkanı olarak su yerine buharlaşma sıcaklığı daha düşük olan organik akışkanların kullanılmasıyla gerçekleşen bir güç üretim sistemidir. Temelde Rankine çevirimi prensibine göre çalışmaktadır. Ancak kullanılan akışkanların buharlaşma sıcaklığı suya göre daha düşük olduğu için özellikle güneș enerjisi, jeotermal enerji ve atık isı sistemlerinde etkin olarak kullanılmaktadır. Doymuş sıvı haldeki akışkan buharlaştırıcıda aldığı ısıyla doymuş kuru buhar haline geçer. Buhar türbin boyunca genleşerek geçerken türbininin enerji üretmesini sağlar. Türbin çıkısındaki buhar yoğuşturucuda doymuş sıvı hale gelir ve bu kapalı çevrimdeki akış pompa yardımıyla devam eder (Şekil 7).

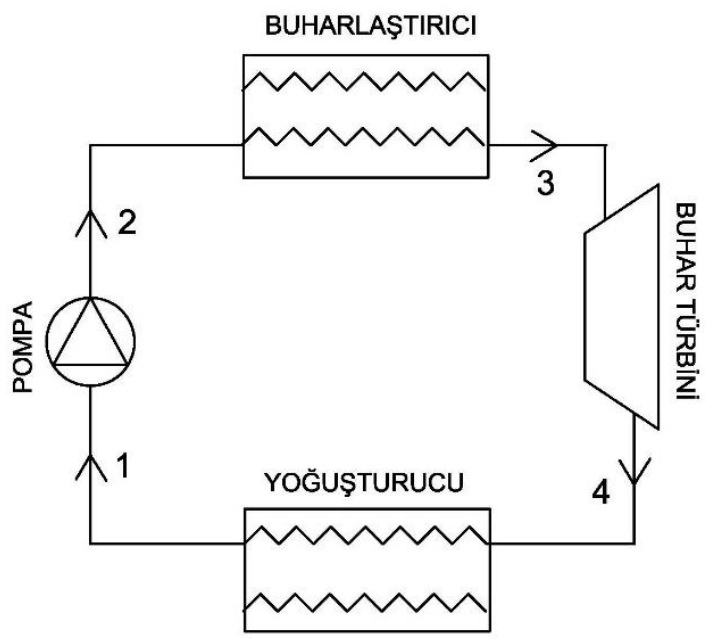

Şekil 7. İdeal Organik Rankine Çevrimi

Organik Rankine çevriminde günümüzde çok çeşitli akışkanlar kullanılmaktadır. Ancak kullanılan bazı akışkanların ODP (Ozone Depletion Potential) ve GWP (Global Warming Potential) değerlerinin yüksek olması bu akışkanların kullanılmasında sınırlama getirmiştir. Ayrıca zehirleyicilik ve yanıcılık özellikleri de akışkan seçimini etkileyen önemli faktörlerdendir.

Bu çalıșmada Ağrı ili Diyadin ilçesinde bulunan Çermik jeotermal enerji sahasında uygulanabilecek $10 \mathrm{~kW}$ gücünde bir Organik Rankine santrali, jeotermal kaynağın bir diğer bölümünde konut ısıtması ve seracılık faaliyetlerinde kullanılması tasarlanmıştır. Mevcut kaynağın sıcaklığı ve bölgenin mevcut hava koşulları dikkate alındığında çalışma akışkanı olarak R-134a kullanılmıştır. Sistem hesaplamaları teorik olarak EES programında yapılmıştır.

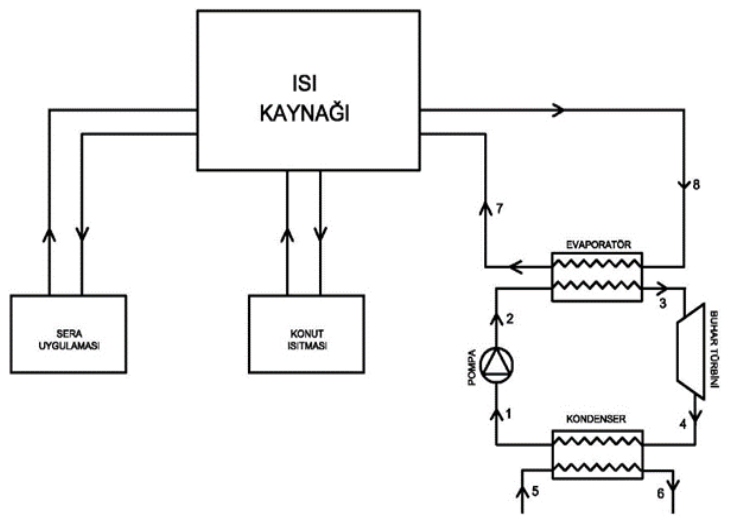

Şekil 8. Sistem Tasarımı

Analizi yapılan sistem Şekil 8' de görülmektedir. 10 kW gücünde bir elektrik enerjisi verebilecek şekilde tasarlanan sistem için öngörülen bazı kabuller aşağıda verilmiștir:

1- Sistem sürekli rejim şartlarında çalışmaktadır. 2-Sistemin çevreyle olan isı etkileşimi ihmal edilmiştir.

3- Sisteme iş giriși ihmal edilmiștir.

4-Pompa ve türbin için izentropik verim kullanılmıştır.

5-Sistemdeki basınç kayıpları ihmal edilmiştir.

Bu kabullere göre sürekli akışlı açık sistemler için kütle dengesi aşağıdaki gibi ifade edilebilir [13].

$\sum \dot{\mathrm{m}}_{\mathrm{g}}-\sum \dot{\mathrm{m}}_{\mathrm{c}}=0$

Buradaki m` kütlesel debiyi ifade etmektedir. Her bir sistem elemanına kütle eşitlikleri yazıldığında sürekli akışlı açık sistem için termodinamiğin birinci yasası veya enerjinin korunumu ilkesi (2) numaralı denklem olarak ifade edilebilir [6].

$\left(\sum \mathrm{Q}_{\mathrm{g}}-\sum \mathrm{Q}_{\varsigma}\right)+\mathrm{W}+\left(\sum \dot{\mathrm{m}}_{\mathrm{g}} \mathrm{h}_{\mathrm{g}}-\sum \dot{\mathrm{m}}_{\mathrm{c}} \mathrm{h}_{\mathrm{c}}\right)=0$

Yukarıdaki denklemlerden hareketle sistem elemanlarına uygulanan termodinamiğin birinci kanununa göre enerji denklemleri aşağıda verilmiştir.

Pompa:

$\mathrm{W}_{\text {pompa }}=\dot{\mathrm{m}}_{\mathrm{akışkan}}\left(\mathrm{h}_{2}-\mathrm{h}_{1}\right)$

Evaporatör:

$$
\mathrm{Q}_{\text {evap }}=\dot{\mathrm{m}}_{\text {akışkan }}\left(\mathrm{h}_{3}-\mathrm{h}_{2}\right)
$$


Türbin:

$\mathrm{W}_{\text {türbin }}=\dot{\mathrm{m}}_{\text {akışkan }}\left(\mathrm{h}_{3}-\mathrm{h}_{4}\right)$

Kondenser:

$\mathrm{Q}_{\mathrm{kond}}=\dot{\mathrm{m}}_{\mathrm{akıskan}}\left(\mathrm{h}_{4}-\mathrm{h}_{1}\right)$

Sistemin Isll verimi:

$\mu_{\text {th }}=\frac{W_{\text {net }}}{Q_{\text {giren }}}$

ile hesaplanır.

Yapılan hesaplamalar sonucu herbir noktanın termodinamik özellikleri Tablo 2' de gösterilmiştir.

Tablo 2. Sistemdeki elemanların termodinamik özellikleri

\begin{tabular}{|c|c|c|c|c|c|}
\hline $\begin{array}{c}\text { No } \\
\mathrm{kt} \\
\mathrm{a}\end{array}$ & $\begin{array}{c}\mathrm{P} \\
(\mathrm{kPa})\end{array}$ & $\begin{array}{c}\mathrm{T} \\
\left({ }^{0} \mathrm{C}\right)\end{array}$ & $\begin{array}{c}\mathrm{h} \\
(\mathrm{kJ} / \mathrm{kg})\end{array}$ & $\begin{array}{c}\mathrm{s} \\
(\mathrm{kJ} / \mathrm{kgK}\end{array}$ & $\begin{array}{c}\mathrm{m} \\
(\mathrm{kg} / \mathrm{s})\end{array}$ \\
\hline 1 & 600 & 21,55 & 81,5 & 0,308 & 0,4685 \\
\hline 2 & 1600 & 22,06 & 82,32 & 0,308 & 0,4685 \\
\hline 3 & 1600 & 70 & 293,3 & 0,9536 & 0,4685 \\
\hline 4 & 600 & 31,11 & 271,9 & 0,9536 & 0,4685 \\
\hline
\end{tabular}

Her bir noktanın hesaplanan termodinamik özelliklerine göre Organik Rankine Çevriminin sonuçları Tablo 3’ de gösterilmiştir.

Tablo 3. ORC Sistemin sonuçları

\begin{tabular}{|c|c|}
\hline W_pompa $(\mathrm{kW})$ & 0,3836 \\
\hline W_türbin $(\mathrm{kW})$ & 10 \\
\hline Q_evaporatör(kW) & 98,94 \\
\hline Q_kondenser(kW) & 89,22 \\
\hline Verim $(\%)$ & 9,73 \\
\hline
\end{tabular}

Denklem ifadelerinden önceki ve sonraki paragraflar arasında birer satır boşluk olmalıdır.

\section{Tartışma ve Sonuc}

Bu çalışmada Ağrı ili Diyadin ilçesinde bulunan ve 1998 yılında sondaj çalışmaları başlatılan jeotermal enerji kaynağı incelenmiștir. Yapılan araștırmalar sonucunda bölgede kurulabilecek Organik Rankine Santrali ve mevcut durumun iyileştirilmesi konusunda bilgiler verilmiștir. Jeotermal enerji kaynağının konut ısıtmasında kullanılmasında ise bölge halkına ekonomik olarak katkı sağladığı görülmektedir. Özellikle kapasitenin artırılması ve mevcut tesislerin geliştirilmesiyle ısınma giderlerinin \%25 oranında azalacağı düşünülmektedir[8,14]. Bölgede jeotermal enerji kaynağının en aktif bir şekilde uygulandığı seracılık faaliyetlerinde ise ihale süreci devam eden Tarıma Dayalı Organize Sera Bölgesinin faaliyete geçmesiyle 2000 kişilik bir istihdam sağlanacağ öngörülmektedir.

Yapılan bu incelemeler sonucunda MTA tarafından sondaj çalıșmalarında yalnızca 1. rezervuara yaklașık 210 metre olarak inildiği görülmüștür. Ancak yeni çalışmalarla ve 2 . rezervuara inilmesiyle jeotermal enerji kaynağının daha yüksek sıcaklıklarda bulunabileceği tahmin edilmektedir. Dolayısıyla bölgedeki jeotermal enerjinin kurulacak bir ORC santralinde kullanılabileceği görülmüștür.

Bölgedeki jeotermal kaynağı ile ilgili gelişmeler neticesinde yapılan bu çalışmanın Ağrı ve Diyadin havzasında bulunan jeotermal enerji kaynaklarının geliştirilmesi konusunda katkı sağlayacağı düşünülmektedir.

\section{Kaynakça}

[1] TUİK 2017 verileri. http://www.tuik.gov.tr. (Erişim Tarihi: 21.12.2017).

[2] T.C. Enerji ve Tabii Kaynaklar Bakanlığ 2017 Verileri. http://www.enerji.gov.tr/trTR/Sayfalar/Elektrik. (Erişim Tarihi: 15.11.2017).

[3] Enerji İşleri Genel Müdürlüğü, Yenilenebilir Enerji, Jeotermal Enerji Nedir? http://www.yegm.gov.tr/yenilenebilir/jeo_ene rji_nedir.aspx. (Erişim Tarihi: 19.12.2017).

[4] Maden Tetkik ve Arama Genel Müdürlüğü, Enerji

Haritaları. http://www.mta.gov.tr/v3.0/hizmetler/jeoter mal-harita. (Erişim Tarihi: 19.12.2017).

[5] Diyadin Haritası. http://www.kgm.gov.tr/SiteCollectionImages/ KGMimages/Haritalar/b12.jpg . (Erişim Tarihi: 20.12.2017).

[6] Erden O., Doğu ve Güneydoğu Anadolu Jeotermal Kaynaklarının, Potansiyeli ve Değerlendirilmesi, Gazi Üniversitesi, Endüstriyel San Eğitim Fakültesi, Ankara, s.101http://www.maden.org.tr/resimler/ekler /69ff987c643b4be_ek.pdf

[7] Kaya, F., 2015. Diyadin(AĞRI) İlçesinde Jeotermal Seracıllk, The Journal of Academic Social Science Studies, Number: 37 , p. 21-38, Doi:http://dx.doi.org/10.9761/JASSS2997.

[8] Akboğa, Y., 2016. Ağrı İbrahim Çeçen Üniversitesi, Sosyal Bilimler Enstitüsü, İktisat Anabilim Dalı, Yüksek Lisans Tezi.

[9] Serpen, Ü., Jeotermal Enerjinin Türkiye ve Dünya'da Kullanımı, Jeotermal Enerji Semineri, İzmir. 
http://www1.mmo.org.tr/resimler/dosya_ekle r/29295d860c049a9_ek.pdf

[10] Ağrı Valiliği. http://www.agri.gov.tr/agridajeotermal-kaynak-bulundu. (Erişim Tarihi: 20.12.2017).

[11] Anonim, 2019. Diyadin Jeotermal Enerji A.Ş. 2019 yllı ücret tarifesi.

[12] Tesisat Dünyası Dergisi, Çeşitli Yakıtların Maliyet Karşılaştırma Tablosu, Aralık 2018. http://www.tesisat.com.tr/yayin/yakitfiyatlari/ (Erişim Tarihi: 27.12.2018).

[13] Çengel, Y. A. , Termodinamik - Mühendislik Yaklaşımıyla, Güven Bilimsel Yayınevi. 